\title{
Analysis of extinction properties as a function of relative humidity using a $\kappa$-EC-Mie model in Nanjing
}

\author{
Zefeng Zhang ${ }^{1}$, Yan Shen ${ }^{2}$, Yanwei $\mathrm{Li}^{1}$, Bin $\mathrm{Zhu}^{1}$, and Xingna $\mathrm{Yu}^{1}$ \\ ${ }^{1}$ Collaborative Innovation Center on Forecast and Evaluation of Meteorological Disasters, Key Laboratory for \\ Aerosol-Cloud-Precipitation of China Meteorological Administration, Nanjing University of Information Science \\ \& Technology, Nanjing, 210044, China \\ ${ }^{2}$ Fenghua Meteorological Bureau of Zhejiang Province, Fenghua 315500, China
}

Correspondence to: Yanwei Li (liyw@ nuist.edu.cn)

Received: 6 February 2016 - Discussion started: 12 May 2016

Revised: 22 November 2016 - Accepted: 6 December 2016 - Published: 28 March 2017

\begin{abstract}
The relationship between relative humidity ( $\mathrm{RH})$ and extinction properties is of widespread concern. In this study, a hygroscopic parameter $(\kappa)$ and the volume fraction of elemental carbon (EC) were used to characterize the chemical characteristics of particles, and a core-shell model was built based on these characteristics. The size distribution, chemical composition, and RH were measured in Nanjing from 15 October to 13 November 2013. The modelderived extinction coefficients of particles were fit with the program of coated spheres according to Bohren and Huffman (2008) (BHCOAT), and the modeled values correlated well with the measurement-derived extinction coefficients $\left(r^{2}=0.81\right)$, which suggested that the core-shell model produced reasonable results. The results show that more than $81 \%$ of the extinction coefficient in Nanjing was due to particles in the $0.2-1.0 \mu \mathrm{m}$ size range. Under dry conditions, the higher mass fraction of particles in the $0.2-1.0 \mu \mathrm{m}$ size range caused the higher extinction coefficient. An increase in RH led to a significant increase in the extinction coefficient, although the increases differed among the different size segments. For $\lambda=550 \mathrm{~nm}$, the extinction coefficient from the $0.01-0.2,0.2-0.5$, and $1.0-2.0 \mu \mathrm{m}$ size ranges increased significantly with the increase in $\mathrm{RH}$, whereas the extinction contributions from the $0.5-1.0$ and $2.0-10.0 \mu \mathrm{m}$ size ranges to the extinction coefficient decreased slightly.
\end{abstract}

\section{Introduction}

Degradation of visibility is likely the most readily perceived impact of aerosol pollution, and it has been used as a visual indicator of ambient air quality (Watson, 2002). Visibility throughout the world has generally decreased in recent decades, especially in Asia. In China, horizontal visibility has significantly decreased since 1980 (Che et al., 2007; Qian and Giorgi, 2000; Qian et al., 2007; Streets et al., 2008; Fu et al., 2013; Yang et al., 2016; Liu et al., 2016). For example, in Guangzhou, one of the largest cities in the Pearl River Delta (PRD), low visibility occurs on 150 days per year (Deng et al., 2008). In the Beijing-Tianjin-Hebei region, the annual average number of continuous haze events has increased, accounting for more than half of the total haze days in a year (Zhang et al., 2015). In the Yangtze River Delta (YRD) region, visibility has decreased at a rate of $2.4 \mathrm{~km} \mathrm{decade}^{-1}$ (Gao et al., 2011). Visibility degradation is mainly caused by the increase in particle number or mass concentration. The increase in particulate pollution can lead to a variety of health problems (cardiovascular disease, respiratory system diseases, etc.) and can furthermore lead to an increase in traffic accidents, which has serious impacts on human health and activities (Tie et al., 2009; Wu et al., 2005; Chang et al., 2009). As a result, visibility problems have received unprecedented attention in recent years.

Under dry conditions, the extinction of particles is the main factor affecting visibility (Covert et al., 1972; Deng et al., 2008; Watson, 2002). The particle number size distribution and chemical composition and relative refractive index 
are the important parameters that affect the optical properties of the particles (Day et al., 2000; Ma et al., 2012; Cheng et al., 2008a; Wen and Yeh, 2010). However, many of the aerosol components are hygroscopic and take up water as a function of the relative humidity (RH) (Clarke et al., 2004; Covert et al., 1972; Swietlicki et al., 2008). When the RH is high, even under subsaturated conditions, the hygroscopic growth of the particles can lead to an increase in size and a decrease in the refractive index, which has significant effects on the extinction properties (Cheng et al., 2008b; Covert et al., 1972; Stock et al., 2011). Furthermore, the physicochemical properties of aerosols can lead to variable hygroscopic growth, and the extinction associated with different particles (with differences in size and chemistry) is significantly different under the same RH. Overall, visibility will decrease when the RH increases (Charlson, 1969; Covert et al., 1972; Stock et al., 2011; Day and Malm, 2001). Some studies show that extinction can increase by more than $100 \%$ when the RH exceeds 70-80\% (Mcmurry, 2000; Zhang and Mcmurry, 1992; Tang, 1996). Therefore, the study of the effect of RH on the extinction coefficient is very important.

Interest in the relationship between aerosol composition, $\mathrm{RH}$, and visibility dates back to at least to the studies of Wright (1940) on the atmospheric opacity over Valentia, Ireland (Wright, 1940). Currently, we can calculate the extinction coefficient accurately based on Mie theory (Bohren and Huffman, 2008) as long as we have information on the overall aerosol population. However, the atmospheric particles are a complex mixture in terms of chemical composition, and it is very difficult to obtain complete data on the physicochemical properties of all the particles. The RH dependency of the extinction coefficients from atmospheric observations can be characterized by fitting a certain formula to the observations. However, this method cannot reflect the differences in physicochemical properties of particles based on the observed aerosol, and fitting curves are different at different sites (Chen et al., 2010; Yu et al., 2016). Another possibility is to use an empirical formula which is based on observed chemical composition and a different RH to calculate the extinction coefficient. However, this empirical formula may not be suitable for other locations. Therefore, we have established a model that has few variables and for which each variable can be obtained based on conventional observations. Our modeling approach consists of three components (Cheng et al., 2006). The first component is elemental carbon (EC), which is the light-absorbing component. The real and imaginary parts of EC are extremely high, and a typical value is 1.8-0.54i (Lee and Tien, 1981; Redemann et al., 2000). Water is the second component, which only scatters the incident radiation with a lowest refractive index of 1.33-0.0i (Levoni et al., 1997). Aside from EC and water, the rest of the aerosol components primarily only scatter light, and their refractive indices are very similar, with a real part of approximately 1.53 and an imaginary part of nearly zero. This component is called a non-light-absorbing component (Lin et al., 2013;
Tang, 1996; Wex et al., 2002). Wex's (2002) study showed that the simplification is reasonable. They found out that, under dry conditions, there was no statistically significant effect on the deviation between the measured and calculated scattering coefficients, when varying the mass fractions of the nearly pure light-scattering compositions within their general concentration levels. Thus, as long as we know the volume fraction of EC and the total volume concentration, we can describe the extinction properties of the particles rather well. However, the particles show hygroscopic growth as the RH increases. Petters and Kreidenweis (2007) proposed a simple hygroscopic parameter, $\kappa$, that can be used to calculate the hygroscopic growth factor (GF) at different levels of RH. $\kappa$ can be considered a function of the volume fraction of the hygroscopic components which are non-light absorbing and the volume fraction of the non-hygroscopic components which are light-absorbing and can be assumed to be EC here. In this way hygroscopic and optical properties can be understood to have a strong linkage. Supposing that non-light-absorbing material is uniformly mixed with water after hygroscopic growth, we can determine the changes in volume of both the real and imaginary parts of the particles, and then we can calculate the extinction coefficient of the particles (Chen et al., 2012). Therefore, we can calculate the extinction properties of the particles accurately at different levels of RH based on the Mie theory according to the three-component model, as long as we obtain the total volume concentration, the volume fraction of EC of the observed aerosols, the hygroscopic parameter $(\kappa)$ of the observed aerosols, and the hypothesized mixed mode of the observed aerosols.

In this study, the volume fraction of EC and the hygroscopic parameter $(\kappa)$ were obtained using film sampling. The film sampling was used to collect data on chemical composition of particles. In this study, the volume fraction of EC was obtained from the film sampling conducted using an Anderson instrument in Nanjing and $\kappa$ was calculated according to the Zdanovskii-Stokes-Robinson (ZSR) rule (Petters and Kreidenweis, 2007; Stokes and Robinson, 1966). The extinction coefficient calculated by the above method had a good relationship with the visibility, which verified the reasonableness of our method. Based on this result, we further explored the growth curve of the extinction coefficient as a function of $\mathrm{RH}$ and probed into the contribution of different size ranges to the extinction coefficient.

\section{Experiment and methods}

\subsection{Measurement location and sampling}

The sampling site was on the roof of a 12-story building at the Nanjing University of Information Science and Technology in the Pukou District of Nanjing $\left(32.207^{\circ} \mathrm{N}\right.$; $\left.118.717^{\circ} \mathrm{E}\right), 40 \mathrm{~m}$ above ground level. Visibility and meteorological parameters were obtained from a meteorolog- 


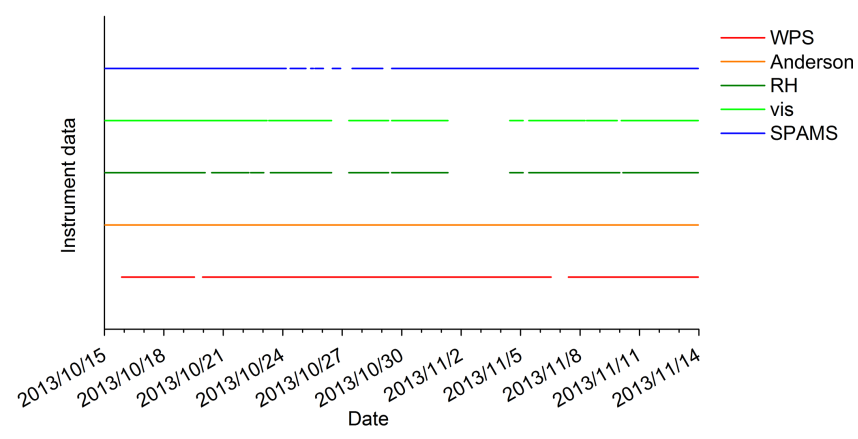

Figure 1. Data coverage during the observation period.

ical station near the sampling site at a distance of less than $1.5 \mathrm{~km}$. The sampling period was from 15 October to 13 November 2013. The periods of instrumental observation are shown in Fig. 1, and the missing data were due to power failure. Moreover, because the aerosol measurements in high $\mathrm{RH}$ are prone to errors, we excluded the data with $\mathrm{RH}>90 \%$ and visibility $<1 \mathrm{~km}$.

\subsection{Instruments and data analysis}

\subsubsection{Instruments}

A wide-range particle spectrometer (WPS; MSP Corporation model 1000XP) is a recently introduced commercial instrument with the unique ability to measure the size distributions of aerosols with diameters from 0.01 to $10 \mu \mathrm{m}$ (Liu, 2010). The WPS combines the principles of differential mobility analysis (DMA), condensation particle counting (CPC), and laser light scattering (LPS). DMA and CPC are used to measure particles' number concentration in the size range of 10$500 \mathrm{~nm}$, and LPS is used to measure particles' number concentration in the range of $0.35-10 \mu \mathrm{m}$. One complete scan of the entire size range with a $3 \mathrm{~s}$ scanning period for each channel takes approximately $5 \mathrm{~min}$. A detailed description is provided by An et al. (2015) and Kang et al. (2013).

Anderson is a nine-stage impact sampler that is produced by the Thermo Electron Corporation (USA). It was used to collect aerosol samples. The sampling flow rate is $28.3 \mathrm{~L} \mathrm{~min}^{-1}$. The size distributions are provided in sections as follows: $\leq 0.43,0.43-0.65,0.65-1.1,1.1-2.1,2.1-3.3$, $3.3-4.7,4.7-5.8,5.8-9.0$, and $>9.0 \mu \mathrm{m}$. We used cellulose filters for ionic species and quartz filters for $\mathrm{EC}$ and $\mathrm{OC}$ (organic carbon). Before use, the quartz was fired for $5 \mathrm{~h}$ at $800^{\circ} \mathrm{C}$ to lower the blank levels of EC and OC. All of the filters were kept in a refrigerator for cryopreservation. Every sample was collected continuously for $23 \mathrm{~h}$ and then kept in a refrigerator before analysis (Zou et al., 2014).

Water-soluble ions were measured with a chromatograph (Metrohm model 850 professional IC, Switzerland). $\mathrm{Na}^{+}$, $\mathrm{NH}_{4}^{+}, \mathrm{Ca}^{2+}, \mathrm{Mg}^{2+}, \mathrm{K}^{+}, \mathrm{F}^{-}, \mathrm{Cl}^{-}, \mathrm{NO}_{2}^{-}, \mathrm{NO}_{3}^{-}$, and $\mathrm{SO}_{4}^{2-}$ were analyzed in this study. The chromatograph includes the use of a column oven, a conductivity detector, an 858 auto-injector and a MagIC net chromatography workstation (Metrohm, Switzerland). The column oven consists of a Metrosep C4150/4.0 separation column and a Metrosep A Supp 5150/4.0 separation column. The eluent was set at $3.2 \mathrm{mmolL}^{-1} \mathrm{Na}_{2} \mathrm{CO}_{3}+1.0 \mathrm{mmolL}^{-1} \mathrm{NaHCO}_{3}$ for anions and $1.7 \mathrm{mmolL}^{-1} \mathrm{HNO}_{3}+0.7 \mathrm{mmolL}^{-1}$ pyridine carboxylic acid for cations. The column temperature was maintained at $30^{\circ} \mathrm{C}$. The flow rate was $1.0 \mathrm{~mL} \mathrm{~min}^{-1}$, and the inject volume was $20 \mu \mathrm{L}$. The detection limits for $\mathrm{Na}^{+}$, $\mathrm{NH}_{4}^{+}, \mathrm{K}^{+}, \mathrm{Mg}^{2+}, \mathrm{Ca}^{2+}, \mathrm{F}^{-}, \mathrm{Cl}^{-}, \mathrm{NO}_{2}^{-}, \mathrm{NO}_{3}^{-}$, and $\mathrm{SO}_{4}^{2-}$ were $0.001,0.005,0.001,0.001,0.001,0.01,0.01,0.01,0.01$, and $0.01 \mathrm{mg} \mathrm{L}^{-1}$, respectively (An et al., 2015).

The EC and OC concentrations were determined with a thermal/optical carbon analyzer (Model 2001A, DRI). The samples were heated to $140,280,480$, and $580^{\circ} \mathrm{C}$ in pure He to determine $\mathrm{OC} 1, \mathrm{OC} 2, \mathrm{OC} 3$, and $\mathrm{OC} 4$, respectively. Then the samples were heated to 580,740 , and $840{ }^{\circ} \mathrm{C}$ in $2 \% \mathrm{O}_{2} / 98 \% \mathrm{He}$ to determine $\mathrm{EC} 1, \mathrm{EC} 2$, and $\mathrm{EC} 3$, respectively. During the heating process, some volatilized organic compounds were converted to carbon dioxide $\left(\mathrm{CO}_{2}\right)$ through an oxidizer (heated manganese dioxide, $\mathrm{MnO}_{2}$ ). $\mathrm{CO}_{2}$ was reduced to methane $\left(\mathrm{CH}_{4}\right)$ through a methanator. Finally, the $\mathrm{CH}_{4}$ equivalents were quantified with a flame ionization detector (FID). The charring effect can transform part of organic carbon into pyrolysis carbon under anaerobic heating. Hence, the correction for pyrolysis was made by continuously monitoring the filter through a $633 \mathrm{~nm} \mathrm{He}-\mathrm{Ne}$ laser in order not to underestimate $\mathrm{OC}$ or include some pyrolyzed $\mathrm{OC}$ in the EC fraction. By monitoring the change in reflected light in the heating process, the initial reflected light is a diacritical point of OC and EC (Miao et al., 2015; Zou et al., 2014).

$\mathrm{PM}_{2.5}$ was detected with a $\beta$-ray particulate continuous monitor (Thermo Fisher) with the working principle of measuring the particles' mass concentration through the $\beta$-ray attenuation. Visibility data were collected with a CJY-1 visibility meter (CAMA Measurement \& Control Equipments Co., Ltd). The visibility meter was used to measure the scattering coefficient of the particles. It has a light source with a wavelength of $940 \mathrm{~nm}$. The accuracy was $\pm 10 \%$ and the data update rate was $1 \mathrm{~min}$. A detailed description of these two instruments was provided previously (Yu et al., 2016).

\subsubsection{Calculation of the hygroscopic parameter $(\kappa)$}

$\kappa$ can be calculated according to many methods (Liu et al., 2014; Miao et al., 2015; Petters and Kreidenweis, 2007). In this study, $\kappa$ was calculated with the ZSR rule (Petters and Kreidenweis, 2007) according to the chemical composition of the particles. For an inorganic component, we considered a system containing $\mathrm{H}^{+}, \mathrm{NH}_{4}^{+}, \mathrm{HSO}_{4}^{-}, \mathrm{SO}_{4}^{2-}$, and $\mathrm{NO}_{3}^{2-}$. We used the ion pairing method from Gysel et al. (2007), and his method is as accurate as the ADDEM model (Topping et al., 2005). For each species, the molecular weight, $\kappa$, and 
Table 1. Properties of each pure material.

\begin{tabular}{lrrr}
\hline & Molecular weight & $\begin{array}{r}\text { Density } \\
\left(\mathrm{g} \mathrm{cm}^{-3}\right)\end{array}$ & $\kappa$ \\
\hline $\mathrm{NH}_{4} \mathrm{NO}_{3}$ & 80.04 & 1.72 & 0.68 \\
$\mathrm{H}_{2} \mathrm{SO}_{4}$ & 98.08 & 1.83 & 1.13 \\
$\mathrm{NH}_{4} \mathrm{HSO}_{4}$ & 115.11 & 1.78 & 0.56 \\
$\left(\mathrm{NH}_{4}\right)_{2} \mathrm{SO}_{4}$ & 132.14 & 1.77 & 0.53 \\
WSOC & & 1.40 & 0.10 \\
\hline
\end{tabular}

density are described in detail in Table 1 (Gysel et al., 2007; Kreidenweis et al., 2008; Petters and Kreidenweis, 2008; Topping et al., 2005). Moreover, we considered the effect of water-soluble organic components (WSOCs) on hygroscopic growth and assumed $\kappa_{\text {org }}=0.1$ (Jimenez et al., 2009; King et al., 2010).

We obtained the mass of each pure species according to the pairing method. Supposing a dry particle density of $1.7 \mathrm{~g} \mathrm{~cm}^{-3}$ (Wehner et al., 2008), we calculated the volume of the dry particles. Aside from the WSOC and the four types of inorganic components in Table 1, we assumed that other components do not contribute to the hygroscopic properties of the aerosols. According to the ZSR rule, $\kappa$ is then given by Eq. (1):

$\kappa=\sum_{i=1}^{N} \kappa_{i} \frac{V_{i, \mathrm{dry}}}{V_{\mathrm{tol}, \mathrm{dry}}}$

where $N$ is the number of pure materials, $\kappa_{i}$ is the hygroscopic parameter of the $i$ th pure material, $v_{i \text {, dry }}$ is the volume of the $i$ th pure material in the dry condition, and $v_{\text {tol, dry }}$ is the total volume of the dry particle.

\subsubsection{Calculation of the hygroscopic growth factor (GF)}

The hygroscopic growth behavior of particles can be described by the theory of Köhler (1936). The theory of Köhler considered the Kelvin effect and Raoult effect and established a relationship between the saturation ratio $S$ (at subsaturation, $S$ is equivalent to $\mathrm{RH}$ ), diameter, and solute properties. Introducing the hygroscopic parameter $\kappa$ (Petters and Kreidenweis, 2007), the hygroscopic growth factor (GF) is determined as follows in Eq. (2):

$\mathrm{GF}=\left(1+\frac{\kappa \cdot S}{\exp \left(\frac{4 \sigma_{\mathrm{S} / \alpha} M_{\mathrm{w}}}{\mathrm{RT} \rho_{\mathrm{w}}}\right)-S}\right)^{\frac{1}{3}}$,

where $M_{\mathrm{w}}$ is the molecular weight of water, $R$ is the ideal gas constant, $\rho_{\mathrm{W}}$ is the density of water, $T$ is the temperature with a value of $20^{\circ} \mathrm{C}$, and $\sigma_{\mathrm{s} / \alpha}$ is assumed to be the surface tension coefficient between water and air (when $T=20^{\circ} \mathrm{C}$, $\left.\sigma_{\mathrm{s} / \alpha}=0.0728 \mathrm{Nm}^{-1}\right)$.

\subsection{Methods}

\subsubsection{Model-derived extinction coefficients}

Under dry conditions, the volume fraction of EC determines the volume fraction of the light-absorbing component and $\kappa$ can describe the hygroscopicity of the particle. These two parameters can be used to calculate the extinction coefficient of a single particle accurately at different RH levels. The physicochemical properties can be different for the same size of particles. It is unrealistic to describe the physicochemical properties of the aerosols individually. Therefore, the internally mixed model, externally mixed model, and core-shell model are often used to describe the chemical composition of aerosol particles in practical studies (Lesins et al., 2002; Cheng et al., 2006; Hao et al., 2010). The calculated results of the extinction coefficient by the core-shell model are usually between those of the internally mixed model and externally mixed model (Hao et al., 2010). Therefore, the coreshell model was used in this study.

In this study, the core-shell model operates under the following assumptions: (1) particles of the same size have the same physicochemical properties, and particles are spherical; (2) under dry conditions, particles are composed of a light-absorbing component (EC, 1.8-0.54i) and a non-lightabsorbing component (1.53-0i), and the EC is a spherical "core" that is always at the center of the particle; (3) GF is a function of $\kappa$ and the hygroscopic uptake of EC is minor, and the non-light-absorbing material is uniformly mixed with water after hygroscopic exposure. Considering that the methods of film sampling and WPS differ significantly in time resolution, we made the following assumptions: (1) the chemical compositions of particles were unchanged for a given diameter segment of the Anderson sampler; (2) the chemical composition of particles remained unchanged over the course of a day.

According to the hypothesis of the core-shell model, we can calculate the model-derived extinction coefficients of the particles using Eq. (3). $N$ was the number of size segments 67 of the WPS $(0.01-10 \mu \mathrm{m})$. In this study, the particles in the range of $0.5-10 \mu \mathrm{m}$ were measured by LPS.

$b_{\text {ext,model-derived }}=\sum_{i=1}^{N} Q_{\text {ext }} \times \pi(r \times \mathrm{GF})_{i}^{2} \times n\left(r_{i}\right)$

The term $n$ represents the number concentration of size segment $N_{i}$ ( $i$ from 1 to 67), and $r_{i}$ is the median radius corresponding to $N_{i}$. $Q_{\text {ext }}$ is an efficiency factor calculated with the BHCOAT program; $Q_{\text {ext }}$ is defined as the extinction cross section of particle divided by the geometric cross section of particle. The input/output parameters of $Q_{\text {ext }}$ and the formulas are listed in Table 2. In Table 2, $X$ is a scale parameter. $D_{0}$ is the diameter of a single particle under dry conditions. $\lambda$ is the incident light wavelength $(\lambda=550 \mathrm{~nm}, 940 \mathrm{~nm})$. The wavelength of the light source of the visibility meter was $940 \mathrm{~nm}$, and the calculated value of $\lambda=940 \mathrm{~nm}$ was used to contrast with the observed value of the visibility meter. GF 
Table 2. Input/output parameters of the efficiency factor $\left(Q_{\text {ext }}\right) . \omega_{0}$ is the single scattering albedo.

\begin{tabular}{ll}
\hline Input parameters & Output parameters \\
\hline$X_{\mathrm{cor}}=\frac{\pi \cdot \sqrt[3]{\frac{V_{\mathrm{EC}}}{V_{\mathrm{tol}}}} \times D_{0}}{\lambda \cdot D_{0} \cdot \mathrm{GF}}$ & $Q_{\mathrm{ext}}$ \\
$X_{\mathrm{man}}=\frac{\lambda}{m_{\mathrm{cor}}}=(1.8,0.54)$ & $\omega_{0}$ \\
$m_{\mathrm{man}}=\left(\frac{1.53+1.33(\mathrm{GF}-1)^{3}}{(\mathrm{GF}-1)^{3}+1}, 0\right)$ & \\
\hline
\end{tabular}

is the hygroscopic growth factor, which was calculated using Eq. (2). If $\mathrm{RH}$ is close to 0 , then $\mathrm{GF}=1$. The complex refractive index was calculated with the volume weighting method after the hygroscopic growth of the particle (Lesins et al., 2002).

\subsubsection{Measurement-derived extinction coefficients}

The meteorological optical range (MOR) is determined as (Zhang, 2007)

$\mathrm{MOR}=\frac{1}{\sigma} \ln \frac{|c|}{\epsilon}=\frac{1}{\sigma} \ln \frac{1}{0.05}=\frac{3.0}{\sigma}$,

where $\sigma$ is the extinction coefficient of the particles, $\varepsilon$ is the visual threshold with a value of 0.05 (MOR is equal to the visibility when $\varepsilon=0.05$ ), and $c$ is the target characteristic coefficient. When the target is black, $c=1$.

Hence, the measured extinction coefficient can be calculated from the visibility as

$b_{\text {ext, } \text { measurement-derived }}=\frac{1}{\text { visibility }} \ln \frac{1}{0.05}=\frac{3.0}{\text { visibility }}$.

\section{Results and discussion}

\subsection{Aerosol properties and visibility during the measurement period}

Time series of RH, visibility, measurement extinction coefficient, and $\mathrm{PM}_{2.5}$ during the observation period are shown in Fig. 2. The measurement extinction coefficient was calculated as 3.0/visibility (Seinfeld and Pandis, 2012). The picture shows that the visibility has a strong negative correlation with $\mathrm{PM}_{2.5}$ and $\mathrm{RH}$ ( $r=-0.7$ and -0.62 , respectively). A time series of number size distribution for dry particles is given by Fig. 3. We find that the periods with a high number concentration had a good consistency with the periods of a high $\mathrm{PM}_{2.5}$ mass concentration $(r=0.7)$. Figure 4 shows the time series of $\kappa$ for different particle size segments. $\kappa$ was calculated according to the ZSR rule, which is described in detail in Sect. 2.2.2. Figure 5 shows the time series of the volume fraction of EC in different size segments, and the volume fraction of EC was calculated using data from the

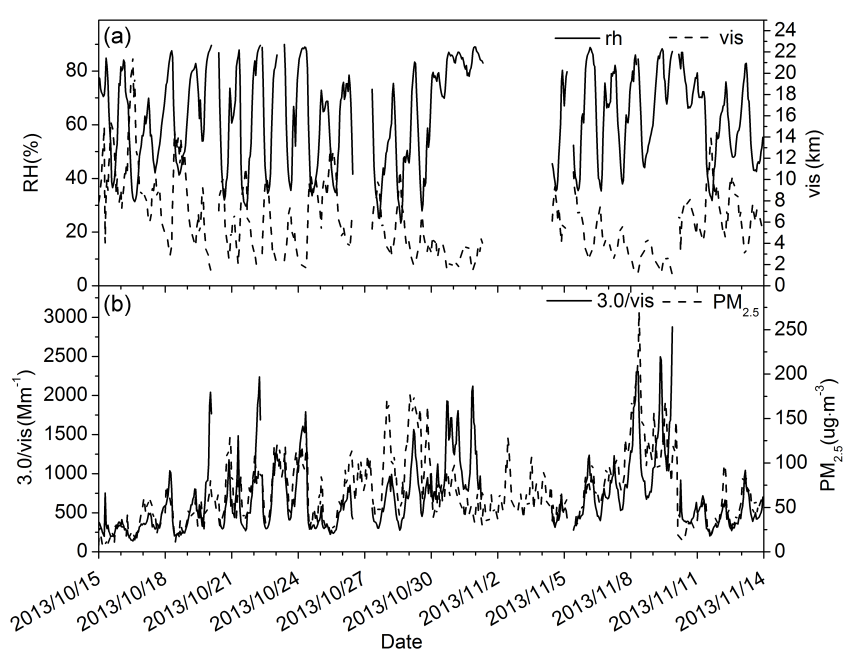

Figure 2. Time series of RH, visibility, extinction coefficient, and $\mathrm{PM}_{2.5}$ during the observation period.

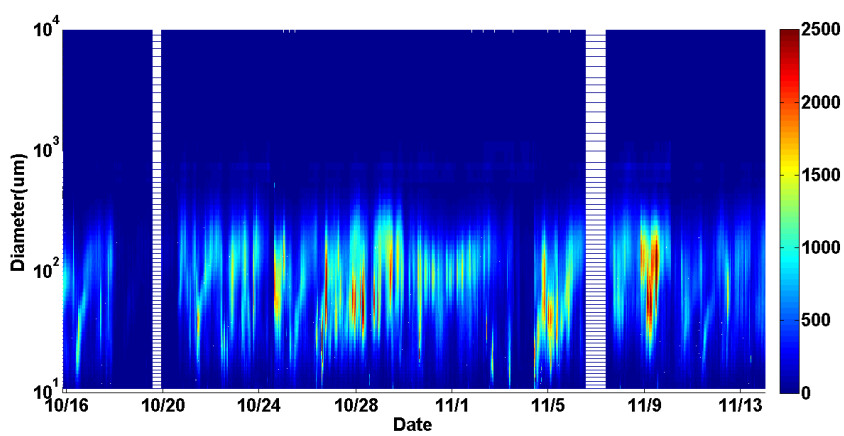

Figure 3. Time series of the number size distribution (dry particles) during the observation period.

Anderson instrument. Figures 4 and 5 show that $\kappa$ and the volume fraction of EC changed over time, but the variation between size segments is higher compared to the variation over time within one size segment especially interactive for $\kappa$. The reason for this difference may be that the particle size was closely related to the sources.

\subsection{Comparative analysis of the model-derived and measurement-derived extinction coefficients of the core-shell model}

Figure 6 shows the relative values of the model and measurement values of the extinction coefficient from the coreshell model. When $\lambda=940 \mathrm{~nm}$, the calculated and measured values of the extinction coefficient were in good agreement $\left(r^{2}=0.81\right)$, which indicated that using the hygroscopic parameter $(\kappa)$ and volume fraction of EC to characterize the chemical characteristics of particles was reasonable. When $\lambda=550 \mathrm{~nm}$, the correlation coefficient of the calculated and measured values $\left(r^{2}=0.714\right)$ was slightly lower compared 


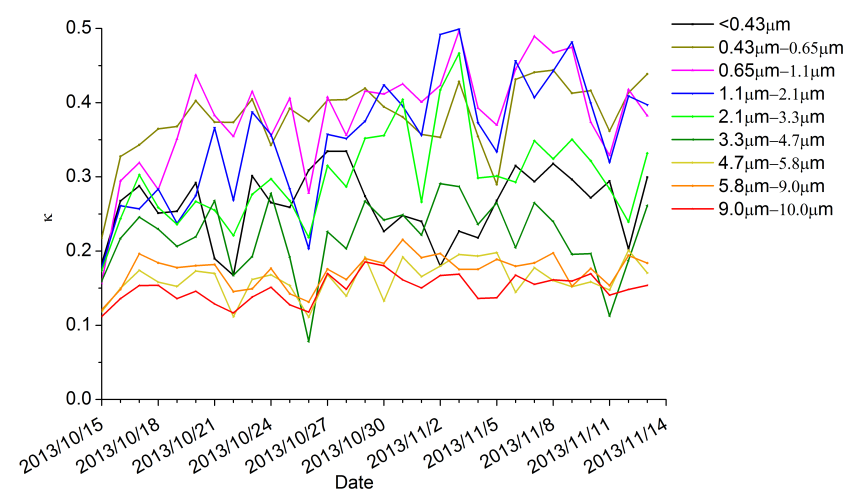

Figure 4. Time series of $\kappa$ in different size segments during the observation period.

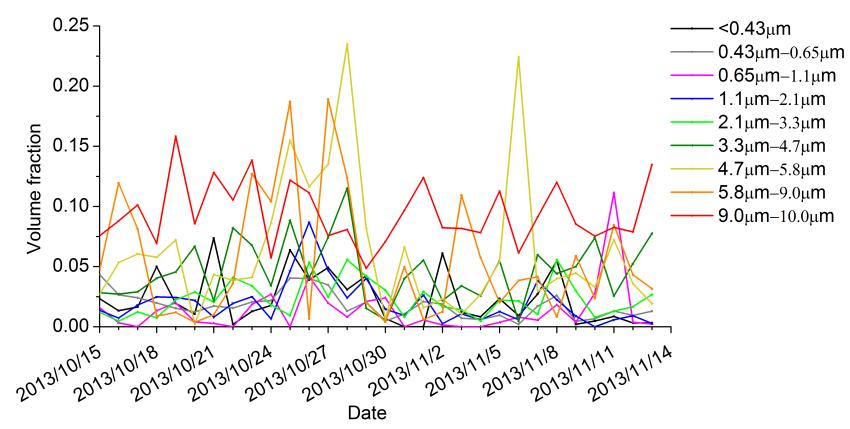

Figure 5. Time series of the volume fraction of EC for different size segments during the observation period.

to $\lambda=940 \mathrm{~nm}$, mainly because that $940 \mathrm{~nm}$ is similar to the light source wavelength of the visibility meter.

Comparing the extinction values of 550 and $940 \mathrm{~nm}$, we found that the model-derived extinction coefficient at $550 \mathrm{~nm}$ was higher, mainly due to the differences in scale parameters, which led to a $Q$ that was larger when $\lambda=550 \mathrm{~nm}$. Because $550 \mathrm{~nm}$ is the most sensitive wavelength for the human eye, the following section focuses on the measurements and calculations at $\lambda=550 \mathrm{~nm}$ for discussion.

\subsection{Contributing fraction of the extinction coefficient for different size segments under dry conditions}

In the core-shell model, we defined $\mathrm{GF}=1$ and then used Eq. (3) to calculate the extinction coefficients of particles under dry conditions. We can calculate the extinction coefficients of the particles in different size segments with different median radii $(r)$. In this study, particle size was divided into five segments: $0.01-0.2,0.2-0.5,0.5-1.0,1.0-2.0$, and $2.0-10.0 \mu \mathrm{m}$. Figure $7 \mathrm{a}$ shows the time series of different size segments to the dry aerosol extinction coefficient, and Fig. 7b shows the relative contribution of different size segments to the dry aerosol extinction coefficient. Figure $7 \mathrm{~b}$ shows that the relative contributions of different size fractions were significantly different. On average, the $0.2-0.5$ and $0.5-1.0 \mu \mathrm{m}$ ranges together contributed more than $81 \%$ of the extinction coefficients, much higher than their total $\mathrm{PM}_{10}$ mass fraction $(45 \%)$. This result suggests that an increase in the proportion of the particles in the $0.2-1.0 \mu \mathrm{m}$ size range in $\mathrm{PM}_{10}$ will result in an even greater increase in the extinction capacity relative to the unit mass of the particles. This result is consistent with the results of Kang et al. (2013). To verify this point, we present Fig. 8, which reflects the extinction capacity relative to the unit mass in different size segments under dry/wet conditions. The $y$ axis is the ratio of the extinction coefficient to the mass concentration for the different size segments. From the picture, we can find that the extinction capacity relative to the unit mass in the $0.2-2 \mu \mathrm{m}$ range was much stronger than that of the other segments. This result explains why the particles in the $0.2-2 \mu \mathrm{m}$ range are the most important for the reduction of the visibility, especially those in the $0.5-1 \mu \mathrm{m}$ range.

\subsection{Effects of relative humidity on the extinction coefficient}

For ambient RH, we can calculate the extinction coefficients of the particles in different size segments using Eq. (3). Figure 9a shows the time series of different size segments to the wet aerosol extinction coefficient, and Fig. 9b shows the relative contributing fraction of different size segments to the wet aerosol extinction coefficient. Comparing Figs. 7 and 9, we found that the extinction coefficients of different size segments to the wet condition were larger than for the particles under dry conditions. Simultaneously, the relative contributing fraction of different size segments to the aerosol extinction coefficient underwent significant changes. Generally speaking, when particles were in the $0.01-0.2,0.2-0.5$, and $1.0-2.0 \mu \mathrm{m}$ size ranges, the relative contribution fraction of the extinction coefficients all increased, especially for fine particles (Table 3). When particles were in the 0.5-1.0 and $2.0-10.0 \mu \mathrm{m}$ size ranges, the relative contribution fraction of the extinction coefficients decreased.

The growth multiples of the extinction coefficients in the different size segments (as shown in Fig. 10a) were calculated through wet aerosol extinction coefficients in the corresponding size segment (as shown in Fig. 9a) divided by the dry aerosol extinction coefficients in the size segment (as shown in Fig. 7a). The $y$ axis represents growth multiples of the extinction coefficients in comparison to the value under dry conditions. The $x$ axis represents the variability of $\mathrm{RH}$. There are five fitting curves in Fig. 10a, representing the different size segments, and the correlation coefficient $\left(r^{2}\right)$ of each fitting curve was larger than 0.9. This result suggests that, on different days, the changes in the enhancement of extinction with the RH in the same size segment were consistent. In addition, the extinction coefficient of the particles in the $0.01-0.2 \mu \mathrm{m}$ size range increased the most with the increased $\mathrm{RH}$, followed by the extinction coefficients of particles in the $0.2-0.5$ and $1.0-2.0 \mu \mathrm{m}$ size ranges. The extinction 
(a)

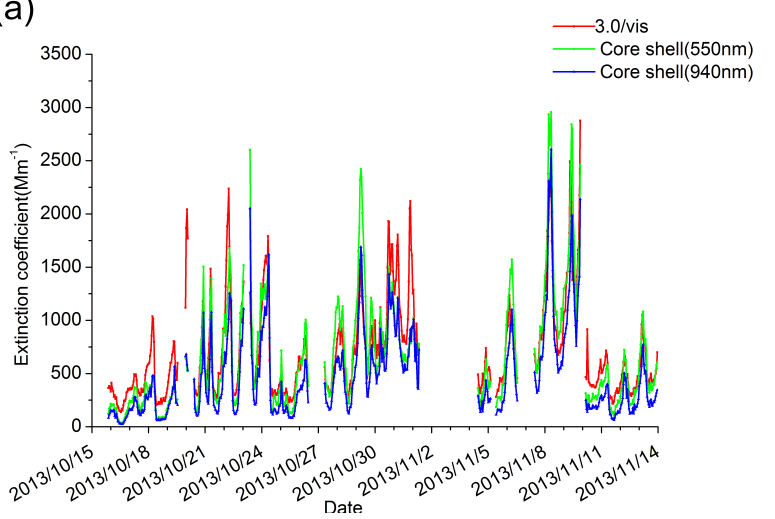

(b)

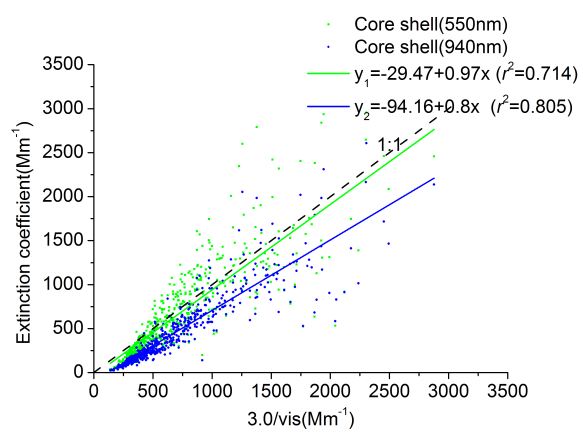

Figure 6. Relationships among the calculated and measured values based on the core-shell model ( $\lambda=550 \mathrm{~nm}, 940 \mathrm{~nm})$.

(a)

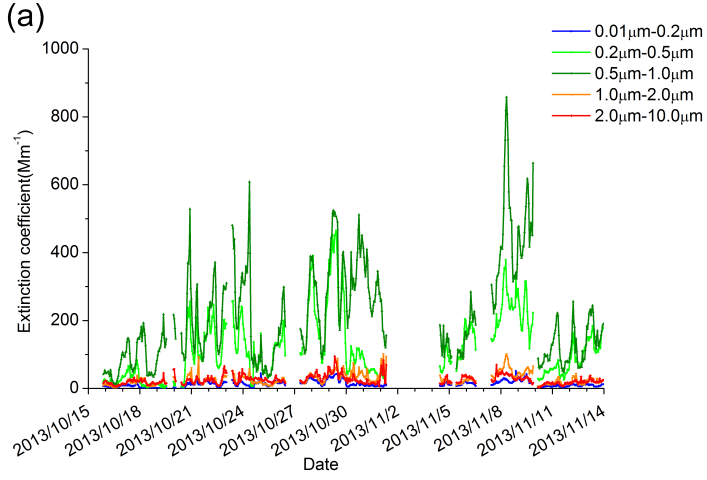

(b)

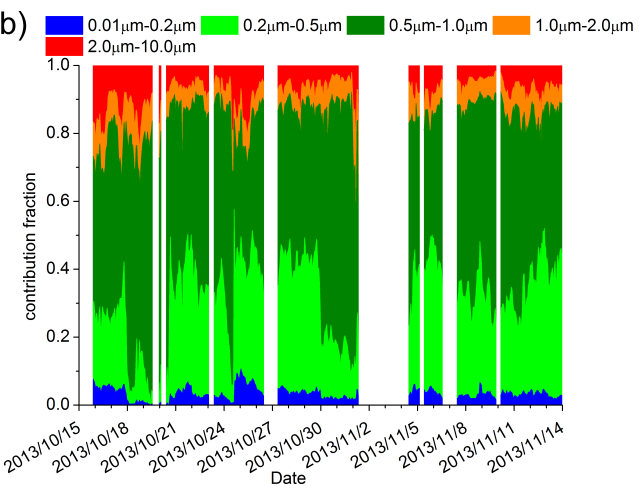

Figure 7. Time series (a) and the relative contributing fraction (b) of different size segments to the dry aerosol extinction coefficient.

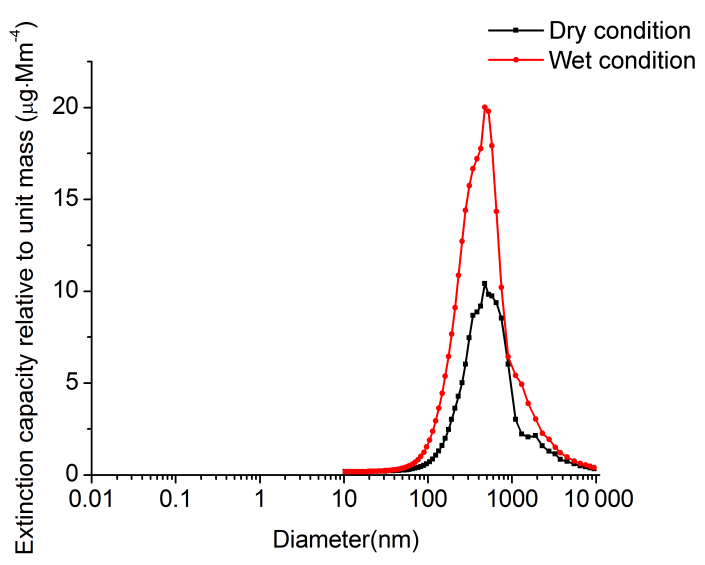

Figure 8. Extinction capacity relative to unit mass in different size segments under dry/wet conditions.

coefficients of particles in the $0.5-1.0$ and $2.0-10.0 \mu \mathrm{m}$ size ranges did not increase with the increased $\mathrm{RH}$.

The impact of RH on the particles was reflected in two aspects: the variability in diameter and the efficiency factor $(Q)$. The growth of particles was determined by the hygroscopic parameter $(\kappa)$. As $\kappa$ increased, GF also increased.
Figure 4 shows the time series of $\kappa$ for different particle sizes during the observations. The particles in the $0.5-1.0 \mu \mathrm{m}$ range had the largest $\kappa$, which means that the variability in the diameter cannot explain the lack of an obvious increase in the extinction coefficients in the $0.5-1.0 \mu \mathrm{m}$ size range. To obtain $Q$ following the influence of $\mathrm{RH}$, we performed the following calculation. Firstly, we assumed that the RH had no effect on $Q$, which means that $Q$ was equivalent to the value under dry conditions. Secondly, we calculated the extinction coefficient of the particles in the different size segments using Eq. (3) (indicated by the letter $b_{\text {ext }}$ ). Extinction coefficients shown in Fig. 9a were divided by $b_{\text {ext }}$ to produce Fig. 10b, which represented the variation in $Q$ with respect to RH. Figure 10b shows that $Q$ increased significantly in the $0.01-0.2,0.2-0.5$, and $1.0-2.0 \mu \mathrm{m}$ size ranges with the increase in RH and that $Q$ declined slightly in the $0.5-1.0$ and $2.0-10.0 \mu \mathrm{m}$ size ranges at high RH values. The fitting curve and the calculated values are significantly different, which reflects how the change in scale parameters coincides with the change in efficiency factors $Q$. For particles in the $0.01-0.2,0.2-0.5,0.5-1.0$, and $1.0-2.0 \mu \mathrm{m}$ size ranges, the correlation coefficients are all high. For particles in the 2.0 $10.0 \mu \mathrm{m}$ range, the correlation coefficient is very low. This 
Table 3. Contribution fraction of the model-derived extinction coefficients under dry/wet conditions and mass fraction in $\mathrm{PM}_{10}$ under dry conditions.

\begin{tabular}{lrrrrr}
\hline & $0.01-0.2 \mu \mathrm{m}$ & $0.2-0.5 \mu \mathrm{m}$ & $0.5-1.0 \mu \mathrm{m}$ & $1.0-2.0 \mu \mathrm{m}$ & $2.0-10.0 \mu \mathrm{m}$ \\
\hline $\begin{array}{l}\text { Contribution fraction of the model-derived } \\
\text { extinction coefficients under dry conditions }\end{array}$ & $3.4 \%$ & $28.3 \%$ & $52.6 \%$ & $7.6 \%$ & $8.0 \%$ \\
\hline $\begin{array}{l}\text { Contribution fraction of the model-derived } \\
\text { extinction coefficients under wet conditions }\end{array}$ & $4.6 \%$ & $33.3 \%$ & $47.6 \%$ & $7.8 \%$ & $6.9 \%$ \\
\hline Mass fraction in $\mathrm{PM}_{10}$ under dry conditions & $8.5 \%$ & $17.4 \%$ & $27.6 \%$ & $13.2 \%$ & $33.3 \%$ \\
\hline
\end{tabular}

(a)

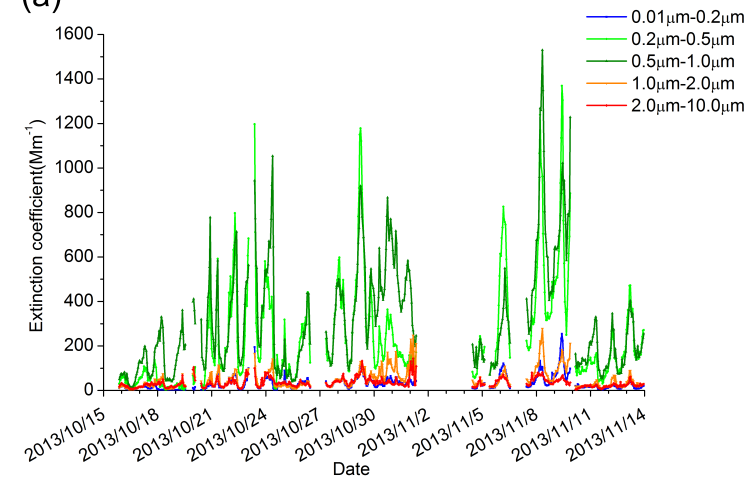

(b) $\square 0.01 \mu \mathrm{m}-0.2 \mu \mathrm{m} \square-0.2 \mu \mathrm{m}-0.5 \mu \mathrm{m} \square 0.5 \mu \mathrm{m}-1.0 \mu \mathrm{m} \quad 1.0 \mu \mathrm{m}-2.0 \mu \mathrm{m}$

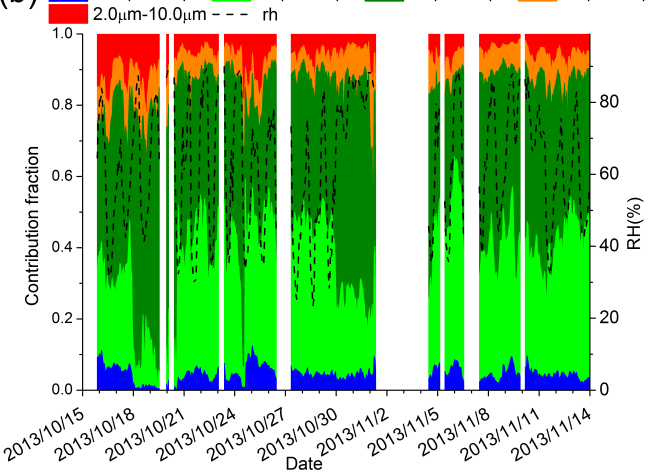

Figure 9. Time series (a) and the relative contributing fraction (b) of different size segments to the wet aerosol extinction coefficient.
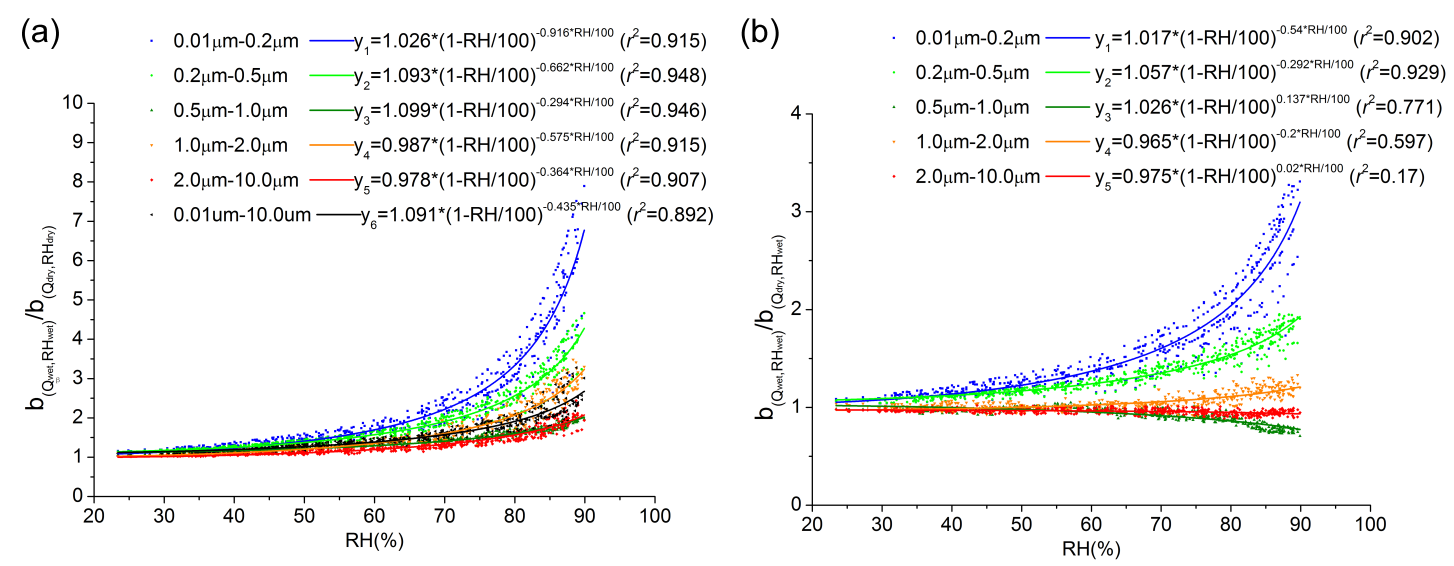

Figure 10. Growth multiples of the extinction coefficient (a) and the change in the efficiency factor (b) in different size segments at ambient relative humidity.

finding suggested that the effect of the variation in the scale parameter on $Q$ was significantly different on different days.

Because the average particle size distribution and chemical composition in each size segment are known, we can calculate the average contribution fraction of the extinction coefficients in each size segment with the increase in RH. The calculation results are shown in Fig. 11, which illustrates that the extinction coefficient was primarily related to particles in the $0.2-0.5$ and $0.5-1.0 \mu \mathrm{m}$ size ranges. Generally speaking, an increase in $\mathrm{RH}$ will lead to an increase in the extinction co- efficient, but the rate of increase in the extinction coefficient was significantly different in each size segment. With an increase in $\mathrm{RH}$, the fractions of the extinction coefficients contributed by the $0.01-0.2,0.2-0.5$, and $1.0-2.0 \mu \mathrm{m}$ size ranges increased considerably, whereas the fractions of the extinction coefficient contributed by the $0.5-1.0$ and $2.0-10.0 \mu \mathrm{m}$ size ranges decreased slightly. 


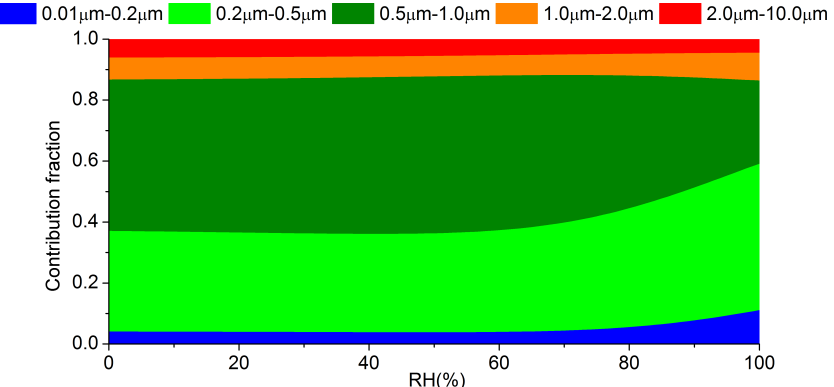

Figure 11. Relationship between the contribution fraction of extinction coefficients in different size segments and relative humidity (RH).

\section{Conclusions}

In this study, a hygroscopic parameter $(\kappa)$ and the volume fraction of elemental carbon (EC) were used to characterize the chemical characteristics of particles and a core-shell model was built based on these characteristics. In the coreshell model, the real part and the imaginary part of the refractive index, the scale parameters were both functions of RH. The extinction coefficients of particles fitted with the BHCOAT program correlated well with the measured values $\left(r^{2}=0.81\right)$ that were derived from the visibility, which suggested that using $\kappa$ and the volume fraction of EC to characterize the chemical characteristics of particles was reasonable.

In the core-shell model, when $\lambda=550 \mathrm{~nm}$, the contribution fractions of the extinction coefficient of different size segments were significantly different. Under the dry condition, more than $81 \%$ of the extinction coefficients in Nanjing were contributed by particles in the $0.2-1.0 \mu \mathrm{m}$ size range, a much higher percentage than their $\mathrm{PM}_{10}$ mass fraction $(45 \%)$. This finding suggested that, for $\mathrm{PM}_{10}$, an increase in the mass proportion of particles in the $0.2-1.0 \mu \mathrm{m}$ size range results in an even greater increase in the extinction capacity.

With the increase in $\mathrm{RH}$, the extinction capacity of the particles will grow significantly. In this study, the formula for the increase in the extinction coefficients in different size segments is given. At a given RH, the growth rate of extinction coefficients differs significantly among the different size segments. The growth rates are related to $\kappa$, and the variation in the scale parameter leads to variations in $Q$, which is the main reason why the growth multiples of the extinction coefficient differ at different $\mathrm{RH}$ values. With the increase in $\mathrm{RH}$, the extinction coefficient contribution fractions increase for particles in the $0.01-0.2,0.2-0.5$, and $1.0-2.0 \mu \mathrm{m}$ size ranges but decrease for particles in the $0.5-1.0$ and $2.0-10.0 \mu \mathrm{m}$ size ranges.

Competing interests. The authors declare that they have no conflict of interest.
Acknowledgements. This work was supported jointly by the National Natural Science Foundation of China (grant nos. 41275152 and 41005071), the National Key Research and Development Program of China (2016YFA0602003), and the National Key Research and Development Project (2016YFC0202400).

Edited by: T. Petäjä

Reviewed by: two anonymous referees

\section{References}

An, J., Wang, H., Shen, L., Zhu, B., Zou, J., Gao, J., and Kang, H.: Characteristics of new particle formation events in Nanjing, China: Effect of water-soluble ions, Atmos. Environ., 108, 32 40, doi:10.1016/j.atmosenv.2015.01.038, 2015.

Bohren, C. F. and Huffman, D. R.: Absorption and Scattering of Light by Small Particles, John Wiley \& Sons, New York, 2008.

Chang, D., Song, Y., and Liu, B.: Visibility trends in six megacities in China 1973-2007, Atmos. Res., 94, 161-167, 2009.

Charlson, R. J.: Atmospheric visibility related to aerosol mass concentration: review, Environ. Sci. Technol., 3, 913-918, 1969.

Che, H., Zhang, X., Li, Y., Zhou, Z., and Qu, J. J.: Horizontal visibility trends in China 1981-2005, Geophys. Res. Lett., 34, L24706, doi:10.1029/2007GL031450, 2007.

Chen, J., Zhao, C. S., Ma, N., Liu, P. F., Göbel, T., Hallbauer, E., Deng, Z. Z., Ran, L., Xu, W. Y., Liang, Z., Liu, H. J., Yan, P., Zhou, X. J., and Wiedensohler, A.: A parameterization of low visibilities for hazy days in the North China Plain, Atmos. Chem. Phys., 12, 4935-4950, doi:10.5194/acp-12-4935-2012, 2012.

Chen, Y., Zhao, D., Chai, F., Liang, G., Xue, Z., Wang, B., Liang, Y., Chen, Y., and Zhang, M.: Correlation between the atmospheric visibility and aerosol fine particles concertrations in Guangzhou and Beijing, China Environ. Sci., 7, 967-971, 2010.

Cheng, Y. F., Eichler, H., Wiedensohler, A., Heintzenberg, J., Zhang, Y. H., Hu, M., Herrmann, H., Zeng, L. M., Liu, S., and Gnauk, T.: Mixing state of elemental carbon and non-lightabsorbing aerosol components derived from in situ particle optical properties at Xinken in Pearl River Delta of China, J. Geophys. Res., 111, D20204, doi:10.1029/2005JD006929, 2006.

Cheng, Y. F., Heintzenberg, J., Wehner, B., Wu, Z. J., Su, H., Hu, M., and Mao, J. T.: Traffic restrictions in Beijing during the Sino-African Summit 2006: aerosol size distribution and visibility compared to long-term in situ observations, Atmos. Chem. Phys., 8, 7583-7594, doi:10.5194/acp-8-7583-2008, 2008a.

Cheng, Y. F., Wiedensohler, A., Eichler, H., Su, H., Gnauk, T., Brüggemann, E., Herrmann, H., Heintzenberg, J., Slanina, J., and Tuch, T.: Aerosol optical properties and related chemical apportionment at Xinken in Pearl River Delta of China, Atmos. Environ., 42, 6351-6372, 2008b.

Clarke, A. D., Shinozuka, Y., Kapustin, V. N., Howell, S., Huebert, B., Doherty, S., Anderson, T., Covert, D., Anderson, J., and Hua, X.: Size distributions and mixtures of dust and black carbon aerosol in Asian outflow: Physiochemistry and optical properties, J. Geophys. Res. Atmos., 109, D15S09, doi:10.1029/2003JD004378, 2004.

Covert, D. S., Charlson, R. J., and Ahlquist, N. C.: A study of the relationship of chemical composition and humidity to light scattering by aerosols, J. Appl. Meteorol., 11, 968-976, 1972. 
Day, D. E. and Malm, W. C.: Aerosol light scattering measurements as a function of relative humidity: a comparison between measurements made at three different sites, Atmos. Environ., 35, 5169-5176, 2001.

Day, D. E., Malm, W. C., and Kreidenweis, S. M.: Aerosol light scattering measurements as a function of relative humidity, J. Air Waste Manage., 50, 710-716, 2000.

Deng, X., Tie, X., Wu, D., Zhou, X., Bi, X., Tan, H., Li, F., and Jiang, C.: Long-term trend of visibility and its characterizations in the Pearl River Delta (PRD) region, China, Atmos. Environ., 42, 1424-1435, doi:10.1016/j.atmosenv.2007.11.025, 2008.

Fu, C., Wu, J., Gao, Y., Zhao, D., and Han, Z.: Consecutive extreme visibility events in China during 1960-2009, Atmos. Environ., 68, 1-7, doi:10.1016/j.atmosenv.2012.11.035, 2013.

Gao, L., Jia, G., Zhang, R., Che, H., Fu, C., Wang, T., Zhang, M., Jiang, H., and Yan, P.: Visual range trends in the Yangtze River Delta Region of China, 1981-2005, J. Air Waste Manage., 61, 843-849, doi:10.3155/1047-3289.61.8.843, 2011.

Gysel, M., Crosier, J., Topping, D. O., Whitehead, J. D., Bower, K. N., Cubison, M. J., Williams, P. I., Flynn, M. J., McFiggans, G. B., and Coe, H.: Closure study between chemical composition and hygroscopic growth of aerosol particles during TORCH2, Atmos. Chem. Phys., 7, 6131-6144, doi:10.5194/acp-7-61312007, 2007.

Hao, L., Yang, W., Wu, T., Shi, G., Zhao, J., and Tan, Y.: Analysis of radiative properties of $\mathrm{BC}$-sulfate aerosols, Plateau Meteorology, 29, 1238-1245, 2010.

Jimenez, J. L., Canagaratna, M. R., Donahue, N. M., Prevot, A. S. H., Zhang, Q., Kroll, J. H., DeCarlo, P. F., Allan, J. D., Coe, H., Ng, N. L., Aiken, A. C., Docherty, K. S., Ulbrich, I. M., Grieshop, A. P., Robinson, A. L., Duplissy, J., Smith, J. D., Wilson, K. R., Lanz, V. A., Hueglin, C., Sun, Y. L., Tian, J., Laaksonen, A., Raatikainen, T., Rautiainen, J., Vaattovaara, P., Ehn, M., Kulmala, M., Tomlinson, J. M., Collins, D. R., Cubison, M. J., Dunlea, J. E., Huffman, J. A., Onasch, T. B., Alfarra, M. R., Williams, P. I., Bower, K., Kondo, Y., Schneider, J., Drewnick, F., Borrmann, S., Weimer, S., Demerjian, K., Salcedo, D., Cottrell, L., Griffin, R., Takami, A., Miyoshi, T., Hatakeyama, S., Shimono, A., Sun, J. Y., Zhang, Y. M., Dzepina, K., Kimmel, J. R., Sueper, D., Jayne, J. T., Herndon, S. C., Trimborn, A. M., Williams, L. R., Wood, E. C., Middlebrook, A. M., Kolb, C. E., Baltensperger, U., and Worsnop, D. R.: Evolution of organic aerosols in the atmosphere, Science, 326, 1525-1529, doi:10.1126/science.1180353, 2009.

Kang, H., Zhu, B., Su, J., Wang, H., Zhang, Q., and Wang, F.: Analysis of a long-lasting haze episode in Nanjing, China, Atmos. Res., 120, 78-87, 2013.

King, S. M., Rosenoern, T., Shilling, J. E., Chen, Q., Wang, Z., Biskos, G., McKinney, K. A., Pöschl, U., and Martin, S. T.: Cloud droplet activation of mixed organic-sulfate particles produced by the photooxidation of isoprene, Atmos. Chem. Phys., 10, 3953-3964, doi:10.5194/acp-10-3953-2010, 2010.

Köhler, H.: The nucleus in and the growth of hygroscopic droplets, T. Faraday Soc., 32, 1152-1161, 1936.

Kreidenweis, S. M., Petters, M. D., and DeMott, P. J.: Singleparameter estimates of aerosol water content, Environ. Res. Lett., 3, 035002, doi:10.1088/1748-9326/3/3/035002, 2008.
Lee, S. C. and Tien, C. L.: Optical constants of soot in hydrocarbon flames, Symposium (International) on Combustion, 18, 11591166, 1981.

Lesins, G., Chylek, P., and Lohmann, U.: A study of internal and external mixing scenarios and its effect on aerosol optical properties and direct radiative forcing, J. Geophys. Res., 107, AAC 51-AAC 5-12, 2002.

Levoni, C., Cervino, M., Guzzi, R., and Torricella, F.: Atmospheric aerosol optical properties: a database of radiative characteristics for different components and classes, Appl. Optics, 36, 80318041, 1997.

Lin, Z. J., Tao, J., Chai, F. H., Fan, S. J., Yue, J. H., Zhu, L. H., Ho, K. F., and Zhang, R. J.: Impact of relative humidity and particles number size distribution on aerosol light extinction in the urban area of Guangzhou, Atmos. Chem. Phys., 13, 1115-1128, doi:10.5194/acp-13-1115-2013, 2013.

Liu, B. Y. H.: A wide-range particle spectrometer for aerosol measurement from $0.010 \mu \mathrm{m}$ to $10 \mu \mathrm{m}$, Aerosol Air Qual. Res., 10, 125-139, doi:10.4209/aaqr.2009.10.0062, 2010.

Liu, H. J., Zhao, C. S., Nekat, B., Ma, N., Wiedensohler, A., van Pinxteren, D., Spindler, G., Müller, K., and Herrmann, H.: Aerosol hygroscopicity derived from size-segregated chemical composition and its parameterization in the North China Plain, Atmos. Chem. Phys., 14, 2525-2539, doi:10.5194/acp-14-25252014, 2014.

Liu, X., Hui, Y., Yin, Z. Y., Wang, Z., Xie, X., and Fang, J.: Deteriorating haze situation and the severe haze episode during December 18-25 of 2013 in Xi'an, China, the worst event on record, Theor. Appl. Climatol., 125, 321-335, doi:10.1007/s007040151509-8, 2016.

Ma, N., Zhao, C. S., Müller, T., Cheng, Y. F., Liu, P. F., Deng, Z. Z., Xu, W. Y., Ran, L., Nekat, B., van Pinxteren, D., Gnauk, T., Müller, K., Herrmann, H., Yan, P., Zhou, X. J., and Wiedensohler, A.: A new method to determine the mixing state of light absorbing carbonaceous using the measured aerosol optical properties and number size distributions, Atmos. Chem. Phys., 12, 23812397, doi:10.5194/acp-12-2381-2012, 2012.

Mcmurry, P. H.: A review of atmospheric aerosol measurements, Atmos. Environ., 34, 1959-1999, 2000.

Miao, Q., Zhang, Z., Li, Y., Duan, Q., Qin, X., and Xu, B.: Size distributions of carbonaceous aerosols and their potential sources at Mt. Huang during Summer, China Environmental Science, 35, 1938-1946, 2015.

Petters, M. D. and Kreidenweis, S. M.: A single parameter representation of hygroscopic growth and cloud condensation nucleus activity, Atmos. Chem. Phys., 7, 1961-1971, doi:10.5194/acp-71961-2007, 2007.

Petters, M. D. and Kreidenweis, S. M.: A single parameter representation of hygroscopic growth and cloud condensation nucleus activity - Part 2: Including solubility, Atmos. Chem. Phys., 8, 6273-6279, doi:10.5194/acp-8-6273-2008, 2008.

Qian, Y. and Giorgi, F.: Regional climatic effects of anthropogenic aerosols? The case of southwestern China, Geophys. Res. Lett., 27, 3521-3524, doi:10.1029/2000GL011942, 2000.

Qian, Y., Wang, W., Leung, L. R., and Kaiser, D. P.: Variability of solar radiation under cloud-free skies in China: The role of aerosols, Geophys. Res. Lett., 34, L12804, doi:10.1029/2006GL028800, 2007. 
Redemann, J., Turco, R. P., Liou, K. N., Russell, P. B., Bergstrom, R. W., Schmid, B., Livingston, J. M., Hobbs, P. V., Hartley, W. S., and Ismail, S.: Retrieving the vertical structure of the effective aerosol complex index of refraction from a combination of aerosol in situ and remote sensing measurements during TARFOX, J. Geophys. Res., 105, 9949-9970, 2000.

Seinfeld, J. H. and Pandis, S. N.: Atmospheric Chemistry and Physics: From Air Pollution to Climate Change, John Wiley \& Sons, New York, 2012.

Stock, M., Cheng, Y. F., Birmili, W., Massling, A., Wehner, B., Müller, T., Leinert, S., Kalivitis, N., Mihalopoulos, N., and Wiedensohler, A.: Hygroscopic properties of atmospheric aerosol particles over the Eastern Mediterranean: implications for regional direct radiative forcing under clean and polluted conditions, Atmos. Chem. Phys., 11, 4251-4271, doi:10.5194/acp11-4251-2011, 2011.

Stokes, R. H. and Robinson, R. A.: Interactions in Aqueous Nonelectrolyte Solutions. I. Solute-Solvent Equilibria, J. Phys. Chem.-US, 70, 2126-2131, doi:10.1021/j100879a010, 1966.

Streets, D. G., Yu, C., Wu, Y., Chin, M., Zhao, Z., Hayasaka, T., and Shi, G.: Aerosol trends over China, 1980-2000, Atmos. Res., 88, 174-182, 2008.

Swietlicki, E., Hansson, H.-C., Hämeri, K., Svenningsson, B., Massling, A., McFiggans, G., McMurry, P. H., Petäjä, T., Tunved, P., Gysel, M., Topping, D., Weingartner, E., Baltensperger, U., Rissler, J., Wiedensohler, A., and Kulmala, M.: Hygroscopic properties of sub-micrometer atmospheric aerosol particles measured with H-TDMA instruments in various environments - a review, Tellus B, 60, 432-469, doi:10.1111/j.16000889.2008.00350.x, 2008.

Tang, I. N.: Chemical and size effects of hygroscopic aerosols on light scattering coefficients, J. Geophys. Res., 101, 19245219250, 1996.

Tie, X., Wu, D., and Brasseur, G.: Lung cancer mortality and exposure to atmospheric aerosol particles in Guangzhou, China, Atmos. Environ., 43, 2375-2377, 2009.

Topping, D. O., McFiggans, G. B., and Coe, H.: A curved multicomponent aerosol hygroscopicity model framework: Part 1 - Inorganic compounds, Atmos. Chem. Phys., 5, 1205-1222, doi:10.5194/acp-5-1205-2005, 2005.

Watson, J. G.: Visibility: Science and regulation, J. Air Waste Manage., 52, 628-713, doi:10.1080/10473289.2002.10470813, 2002.
Wehner, B., Birmili, W., Ditas, F., Wu, Z., Hu, M., Liu, X., Mao, J., Sugimoto, N., and Wiedensohler, A.: Relationships between submicrometer particulate air pollution and air mass history in Beijing, China, 2004-2006, Atmos. Chem. Phys., 8, 6155-6168, doi:10.5194/acp-8-6155-2008, 2008.

Wen, C.-C. and Yeh, H.-H.: Comparative influences of airborne pollutants and meteorological parameters on atmospheric visibility and turbidity, Atmos. Res., 96, 496-509, 2010.

Wex, H., Neusüß, C., Wendisch, M., Stratmann, F., Koziar, C., Keil, A., Wiedensohler, A., and Ebert, M.: Particle scattering, backscattering, and absorption coefficients: An in situ closure and sensitivity study, J. Geophys. Res., 107, 8122, doi:10.1029/2000JD000234, 2002.

Wright, H. L.: Atmospheric opacity at valentia, Q. J. Roy. Meteor. Soc., 66, 209-213, 1940.

Wu, D., Tie, X., Li, C., Ying, Z., Lau, A. K.-H., Huang, J., Deng, X., and Bi, X.: An extremely low visibility event over the Guangzhou region: A case study, Atmos. Environ., 39, 6568-6577, 2005.

Yang, Y. Q., Wang, J. Z., Gong, S. L., Zhang, X. Y., Wang, H., Wang, Y. Q., Wang, J., Li, D., and Guo, J. P.: PLAM - a meteorological pollution index for air quality and its applications in fog-haze forecasts in North China, Atmos. Chem. Phys., 16, 1353-1364, doi:10.5194/acp-16-1353-2016, 2016.

Yu, X., Ma, J., An, J., Yuan, L., Zhu, B., Liu, D., Wang, J., Yang, Y., and Cui, H.: Impacts of meteorological condition and aerosol chemical compositions on visibility impairment in Nanjing, China, J. Clean. Prod., 131, 112-120, doi:10.1016/j.jclepro.2016.05.067, 2016.

Zhang, W.: Principle and method of atmospheric detection, 29-32, Meteorological Press, Beijing, 2007.

Zhang, X. and Mcmurry, P. H.: Evaporative losses of fine particulate nitrates during sampling, Atmos. Environ., 26, 3305-3312, 1992.

Zhang, Y., Zhang, P., Wang, J., Qu, E., Liu, Q., and Li, G.: Climatic characteristics of persistent haze events over Jingjinji during 1981-2013, Meteorological Monthly, 41, 311-318, 2015.

Zou, J., An, J., Wang, H., Shao, P., Duan, Q., Xue, G., and Pang, B.: Distribution characteristics of pollution gases and water soluble ion in aerosol during the Asian youth games of Nanjing, China, Environ. Sci., 35, 4044-4051, 2014. 